\title{
Lepadarq
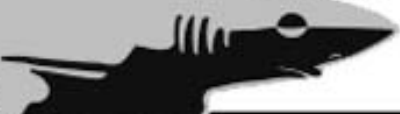

\section{RUÍNA E MATERIALIDADE: UMA ARQUEOLOGIA VISUAL ACERCA DA TRANSFORMAÇÃO DE ANTIGOS ESPAÇOS DO MUSEU DE ARQUEOLOGIA DE XINGÓ}

RUIN AND MATERIALITY: A VISUAL ARCHAEOLOGY ABOUT THE TRANSFORMATION OF OLD SPACES FROM MUSEU DE ARQUEOLOGIA DE XINGÓ

Marcus Vinícius Pereira Santos da Silva

Como citar este texto:

SILVA, Marcus Vinícius Pereira Santos da. Ruína e materialidade: uma Arqueologia visual acerca da transformação de antigos espaços do Museu de Arqueologia de Xingó. In: Cadernos do Lepaarq, v. XVI, n.32., p. 190-200, Jul-Dez. 2019. 


\title{
Ruína e materialidade: uma Arqueologia visual acerca da transformação de antigos espaços do Museu de Arqueologia de Xingó
}

\author{
Marcus Vinícius Pereira Santos da Silva ${ }^{\mathrm{a}}$
}

Resumo: O ensaio visual a seguir preconiza à escavação imagética de antigos espaços do Museu de Arqueologia de Xingó (MAX-UFS) que, em decorrência de seu abandono, transformaram-se, ao longo do tempo, em ambientes de ruína. A argumentação apresentada aqui busca não apenas legar uma maior importância à decadência como um fenômeno de transformação espacial, mas comoa materialidade manifestada em uma ruína moderna contribui para a formação do valor histórico e arqueológico desta. Neste trabalho a fotografia é encarada enquanto testemunha do encontro ocorrido entre o arqueólogo e a cultura material, traduzindo a maneira pela qual ele escolhe representa-lo e, consequentemente, como esta escolha influencia na interpretação arqueológica produzida por intermédio de uma documentação visual.

\section{Palavras Chave:}

Arqueologia, Fotografia, Ruína, Materialidade

\begin{abstract}
The following visual essay describes an imaging excavation of old spaces at the Museu de Arqueologia de Xingó that, due to their abandonment over time, are now in ruins. The argument presented here seeks not only to attach greater importance to decadence as a phenomenon of spatial transformation, but also how the materiality manifested in modern ruins contributes to the formation of their historical and archaeological value. In this work, photography bears witness to the encounter between archaeologist and material culture, translating how it is represented and how this influences the archaeological interpretation produced through a visual document.
\end{abstract}

\section{Keywords:}

Archaeology, Photography, Ruin, Materiality

\footnotetext{
${ }^{a}$ Bacharel em Arqueologia pelo Departamento de Arqueologia da Universidade Federal de Sergipe (DARQ/UFS), Brasil. Email: vinicius.fotoarqueologia@gmail.com
} 


\section{INTRODUÇÃO}

Este trabalho parte de um esforço daquilo que o arqueólogo Michael Shanks define por sensibilidade arqueológica (2012a; 2012b). Desta forma, a prática da Arqueologia pode ser caracterizada enquanto um exercício de imaginação por parte do arqueólogo, uma vez que ele, no presente, se debruça sobre uma série de vestígios materiais como um meio para entender aquilo que aconteceu. Em outras palavras: o fazer arqueológico nada mais é do que uma atitude contemporânea frente ao interesse de compreender o passado humano através de seus remanescentes.

Este ensaio, partindo da ideia de Shanks (1997), configura-se enquanto Arqueografia, ou seja, dar uma forma visual (fotográfica) ao vestígio arqueológico. Aqui as imagens assumem a função de um photowork, pois, tendo sua produção voltada à pesquisa arqueológica, tal conjunto caracteriza um veículo interpretativo, podendo ser pensado enquanto construção cultural em oposição à documentação objetiva. Photowork, portanto, denota uma coleção de registros fotográficos produzidos pelo arqueólogo, uma evidencia material do passado que transcreve as reflexões (teóricas e práticas) adotadas por ele.

A proposta apresentada aqui versa sobre a exploração imagética de alguns espaços que, embora esquecidos ou destituídos de sua função original, mantém-se de pé carregando uma parte substancial da vida do Museu de Arqueologia de Xingó. De fato, há aqui uma associação entre o abandono e a decadência dos ambientes e materiais retratados, documentando, por um lado, um momento do tempo e da história de cada local, por outro, acentuando a beleza visual da deterioração da cadeia de processos que levam à formação destes lugares.

O Museu de Arqueologia de Xingó nasceu em decorrência dos trabalhos de salvamento arqueológico efetuados entre o final dos anos 1980 e parte dos anos 1990 na região conhecida como Baixo São Francisco, compreendendo os estados de Sergipe e Alagoas. A instituição que surgiu como um bastião para salvaguardar os materiais recuperados nos trabalhos de escavação do PAX (Projeto Arqueológico de Xingó) e dar continuidade ao desenvolvimento da pesquisa arqueológica da área, com o tempo, pode-se dizer, tornou-se evidencia arqueológica.

Observa-se que em virtude das diversas reformas estruturais empreendidas no prédio e em seus anexos, muitas das salas que ora foram laboratórios, espaços comunais ou mesmo depósito de restos arqueológicos acabaram por serem convertidas em repositórios de entulho, almoxarifado, ambientes vazios ou estoque de material não estudado ou abandonado. Tais transformações carregam traços que evidenciam o ciclo de existência do museu. A não-vida destes espaços e das coisas que ali jazem funcionam como testemunhas do passado da instituição, e além, nos contam como no presente estes locais têm adquirido novas funções ou são deixados permanentemente de lado.

Uma vez que a materialidade intrínseca à uma ruína contemporânea e seus aspectos implícitos sejam o foco da discussão levantada, concomitante à ideia da fotografia como um meio para representa-la, tem-se amparo nos argumentos levantados por Bjønar Olsen e Póra Pétursdóttir (2014). Neste caso, a percepção de ruína toma a liberdade de se afastar do significado comumente empregado pelo uso da palavra: o antigo, o monumental, aquilo que é clássico e que carrega valores contemplativos e estéticos. Assim, a condição sine qua non de uma ruína contemporânea subsiste em seu estado atemporal, onde as camadas do passado, do presente e do futuro se chocam mutuamente. Paredes, janelas, estruturas de gesso, madeira ou ferro e outros objetos funcionam como uma escavação, pois instigam memórias e significados que, quando coadunados, podem desencadear uma série de interpretações. Tais processos subjacentes à decadência e à ruína estão cristalizados nestes locais e em seus objetos, promovendo, desta maneira, reflexões sobre sua história e sua interação com as pessoas.

As imagens mostradas buscam transmitir uma maior profundidade com relação ao uso deste tipo de ferramenta pela Arqueologia, considerando desta maneira o engajamento do registro fotográfico não apenas enquanto veículo documental, 
mas como um meio de interação com a cultura material. Aqui a imagem assume uma postura mediadora do envolvimento entre o autor e a materialidade expressa na ruína. Consequentemente, tal abordagem acaba desafiando a "iconofobia" que ainda persiste no âmbito arqueológico, onde a fotografia aparece geralmente subordinada ao texto, deixada em segundo plano, servindo enquanto um dispositivo ilustrativo suplementar. Sendo assim, a procura por métodos alternativos de aplicação do documento fotográfico junto à Arqueologia preterida por este trabalho procura viabilizar a importância de reconhecer a experiência, a integridade e a alteridade daquilo que é encontrado. A visualidade mostra-se, portanto, segundo Olsen \& Pétursdóttir (2014), como uma consequência do engajamento com o ambiente e as coisas, funcionando não apenas enquanto representação deste contato, mas também como um compromisso para com ele.

Esta postura compromissada frente as coisas que estão quebradas ou esquecidas, como encontradas em uma ruína moderna, tem respaldo em estudos que se valem de uma Arqueologia da Contemporaneidade para entender o valor arqueológico manifestado por estes espaços, uma vez que tal posicionamento está sincronicamente alinhado aquilo que é atual. Sob esta perspectiva, o presente trabalho apoia-se, respectivamente, nas proposições levantadas por Victor Buchli \& Gavin Lucas (2001) e Alfredo Gonzáles-Ruibal (2008) como um meio para entender o conjunto de mudanças sofridas pelos espaços retratados através das fotografias aqui expostas. Levando em consideração o objeto de estudo fomentado por esta discussão, entende-se que os argumentos colocados por estes autores promovem o entrelaçamento de informações etnográficas, patrimoniais, artísticas ou históricas como um meio para interpretar diversos fenômenos relacionados a modernidade. A Arqueologia da Contemporaneidade, portanto, acaba evidenciando um ponto de vista radical, pois não apenas aceita, como trabalha em cima da natureza perturbadora, parcial e estranha do registro arqueológico.

Uma vez que estejam organizadas sob a forma de um ensaio de cunho visual, as fotografias mostradas neste trabalho têm amparo nas ideias levantadas por Beatriz Cunha Fiúza e Cristina Parente (2008) e Anne Darling (2014), cuja premissa parte do conceito de um conjunto imagético estruturado a partir de imagens que dialoguem entre si, exibindo um tema em comum onde a coesão denotada por cada elemento permite a leitura de todo o conjunto. Um ensaio, neste caso, configura um meio para construir uma narrativa a partir de uma série de imagens. No âmbito deste texto visual as fotografias não necessariamente precisam ser apresentadas em ordem cronológica para serem lidas e entendidas, pois sua finalidade está fundamentada na transmissão de uma mensagem que instigue o leitor, levando-o a questionar e promover uma reflexão a respeito do tema.

Embora possa ser descrito enquanto uma proposta arqueológica acerca da utilização da imagem a partir de uma narrativa visual, o respaldo para apresenta-las é buscado na Antropologia Visual, especialmente no princípio concebido por Luiz Eduardo Robinson Achutti em suas obras Fotoetnografia: um estudo de Antropologia Visual sobre cotidiano, lixo e trabalho (1997) e Fotoetnografia da Biblioteca Jardim (2004). Basicamente, uma vez que a produção fotográfica pressuponha a construção de uma narrativa imagética, pensada e montada coerentemente de acordo, a fotografia deve assumir independência do texto. Ou seja, ela deve falar por si mesma, prescindindo o uso de legendas ou comentários que denotem alguma explicação. No entanto, argumenta Achutti, não há necessariamente algum impedimento para que sejam anexadas informações textuais que convidem o leitor a se situar contextualmente, instigando-o a mergulhar no mundo de imagens aberto a sua frente. Ainda de acordo com Biazus (2006), a adoção desta ideia promove um emprego mais ativo do registro fotográfico, pois ao considerar o uso de conjuntos ou sequencias de imagens, abrem-se possibilidades de leituras mais completas e diversificadas, afastando assim o medo imputado a um uso mais aprofundado do documento fotográfico enquanto agente de sentido.

Ainda que possa ser definido como tal, este ensaio não discute, em sua totalidade, sobre a potencialidade de alcance do documento fotográfico dentro da Arqueologia, ou mesmo para os demais campos mencionados ao longo do texto. Trata- 
se, na verdade, de buscar uma abordagem alternativa à cultura material, partindo da ideia de visualidade enquanto alicerce metodológico e interpretativo desta. Em outras palavras: "Ruína e Materialidade" funciona como uma intercessão entre a imagem enquanto representação artística e como esta pode ser usada enquanto instrumento para de reflexão arqueológica.

Por fim, como dito anteriormente, as fotografias exibidas aqui procuram fazer conexões entre o passado e o presente através dos espaços retratados e da cultura material existente nos mesmos. São vislumbres temporais da história do Museu de Arqueologia de Xingó que se manifestam através de estruturas, objetos, detalhes e suas consequentes transformações. São traços de vida e de morte, um diálogo entre o efêmero e o arqueológico transmutado em experiência visual. Em última instância, é o uso da fotografia como um veículo para entender a realidade de um lugar que vem sendo continuamente transformado através do tempo.
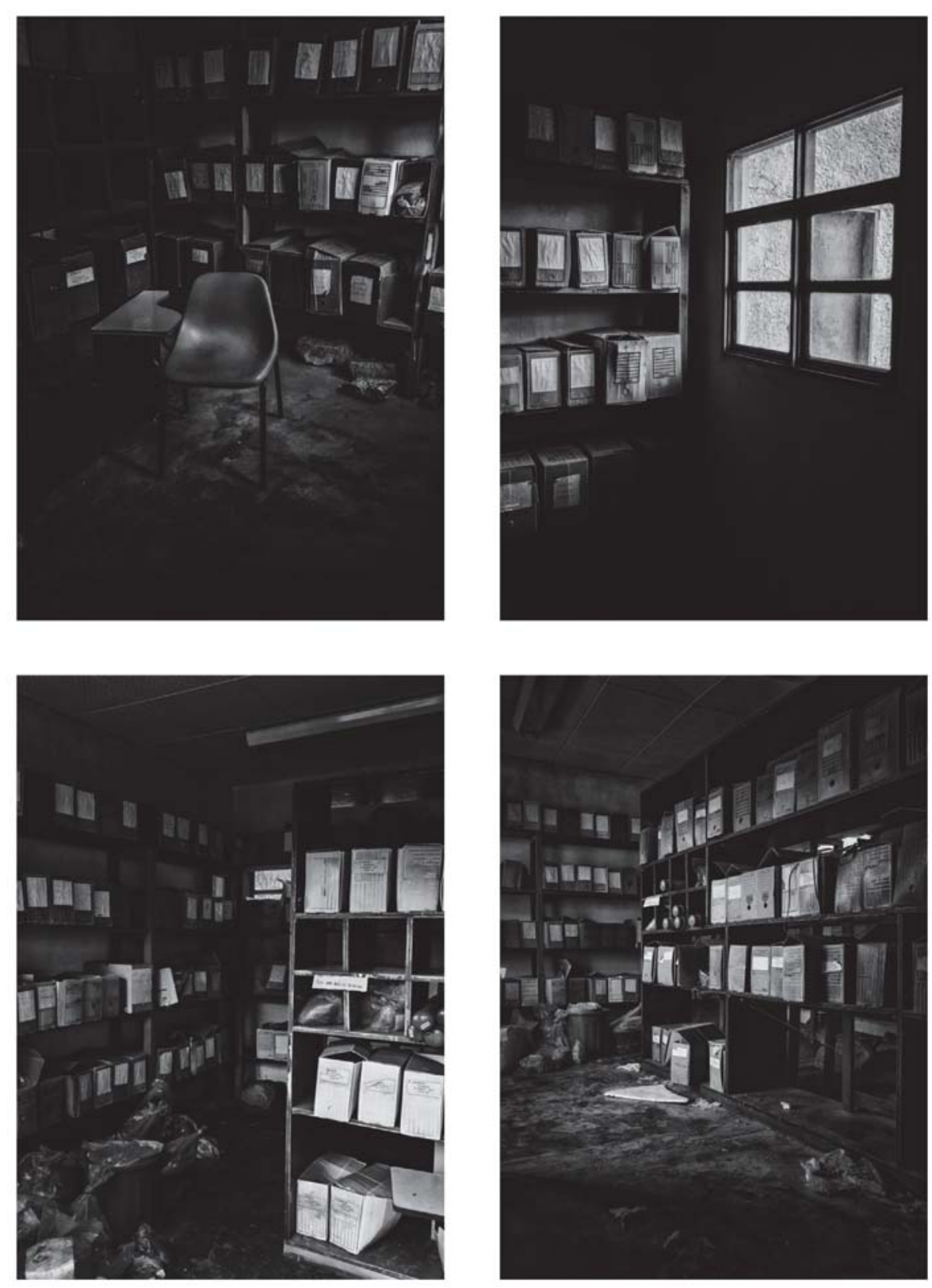

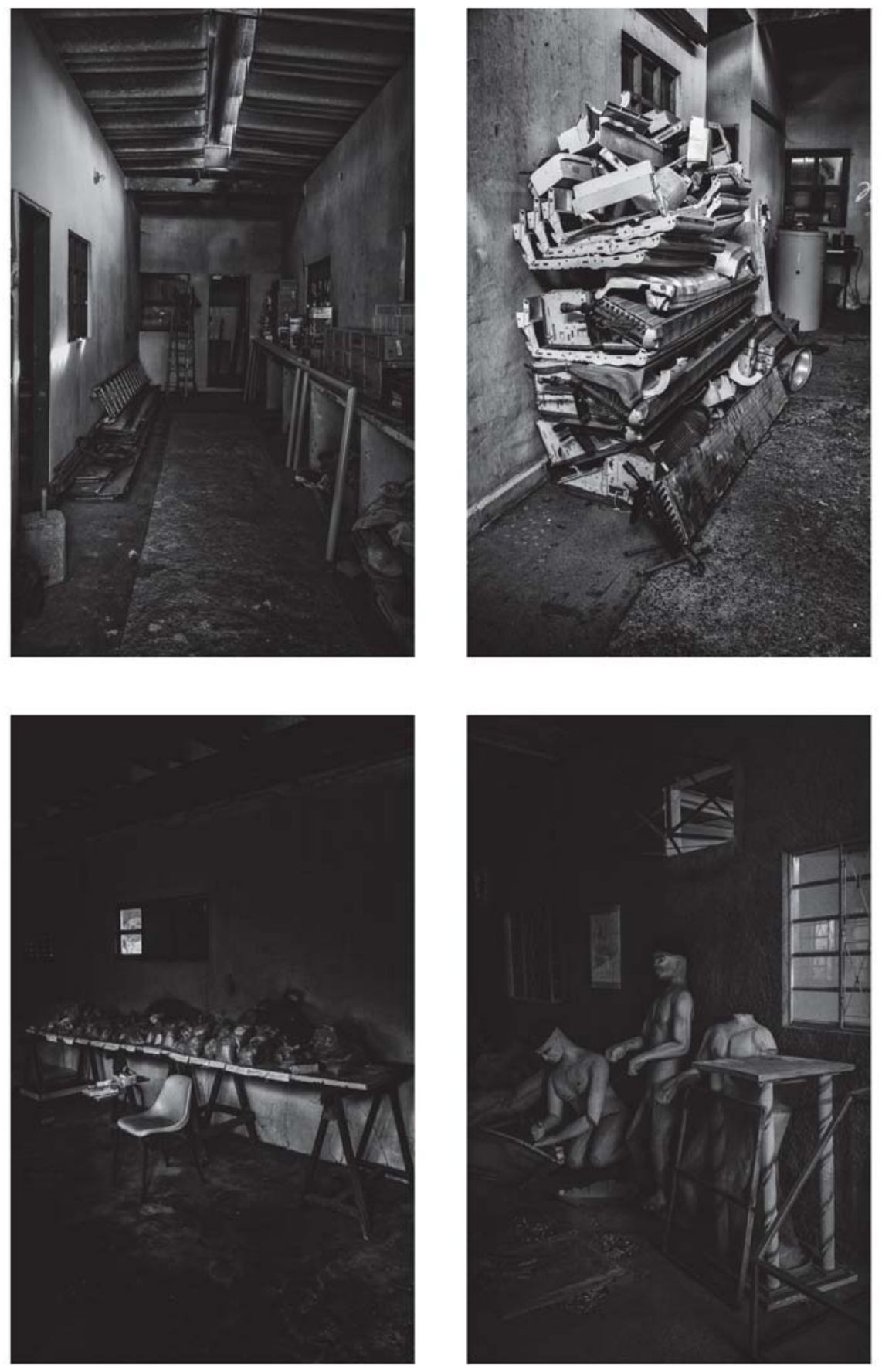

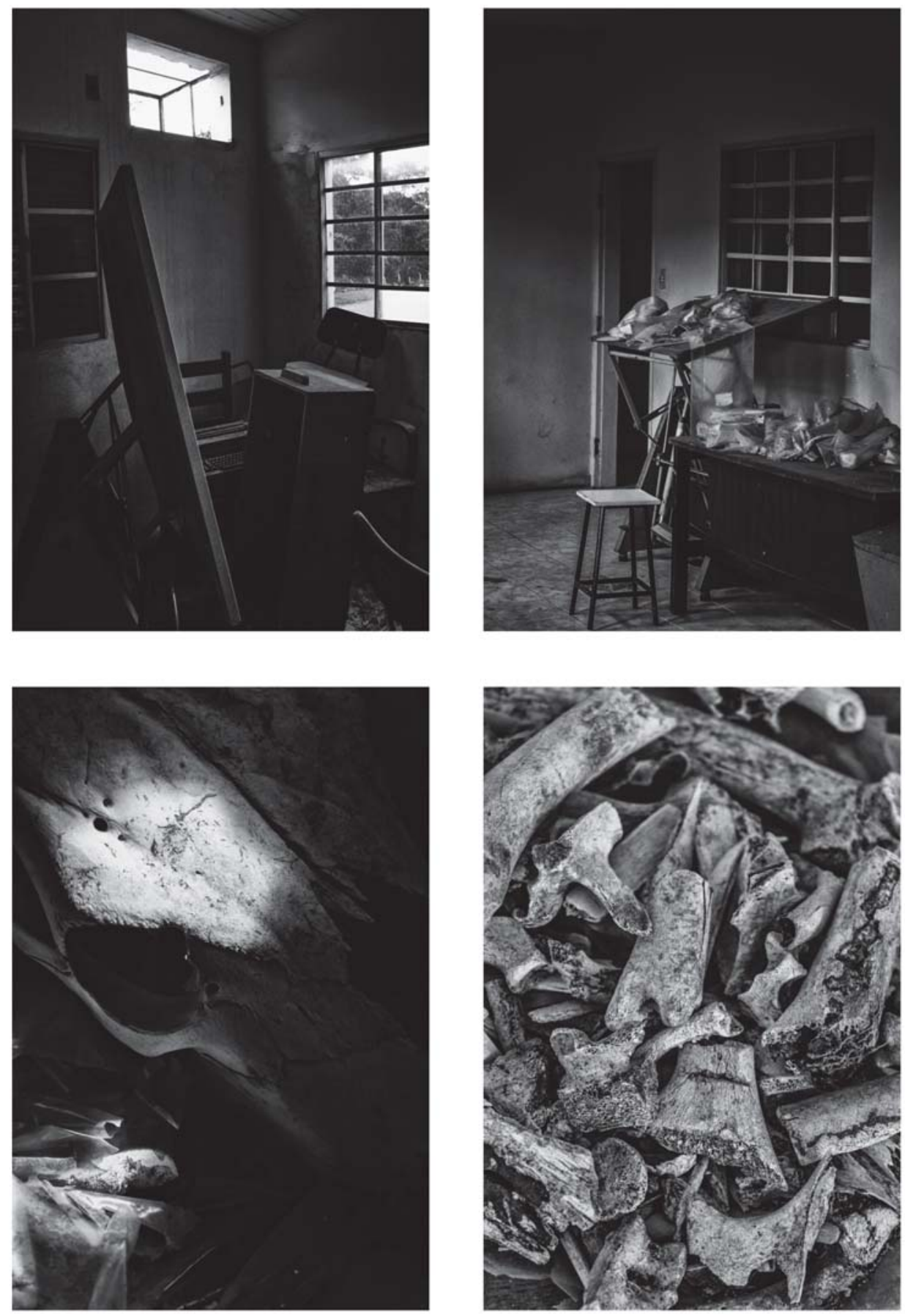

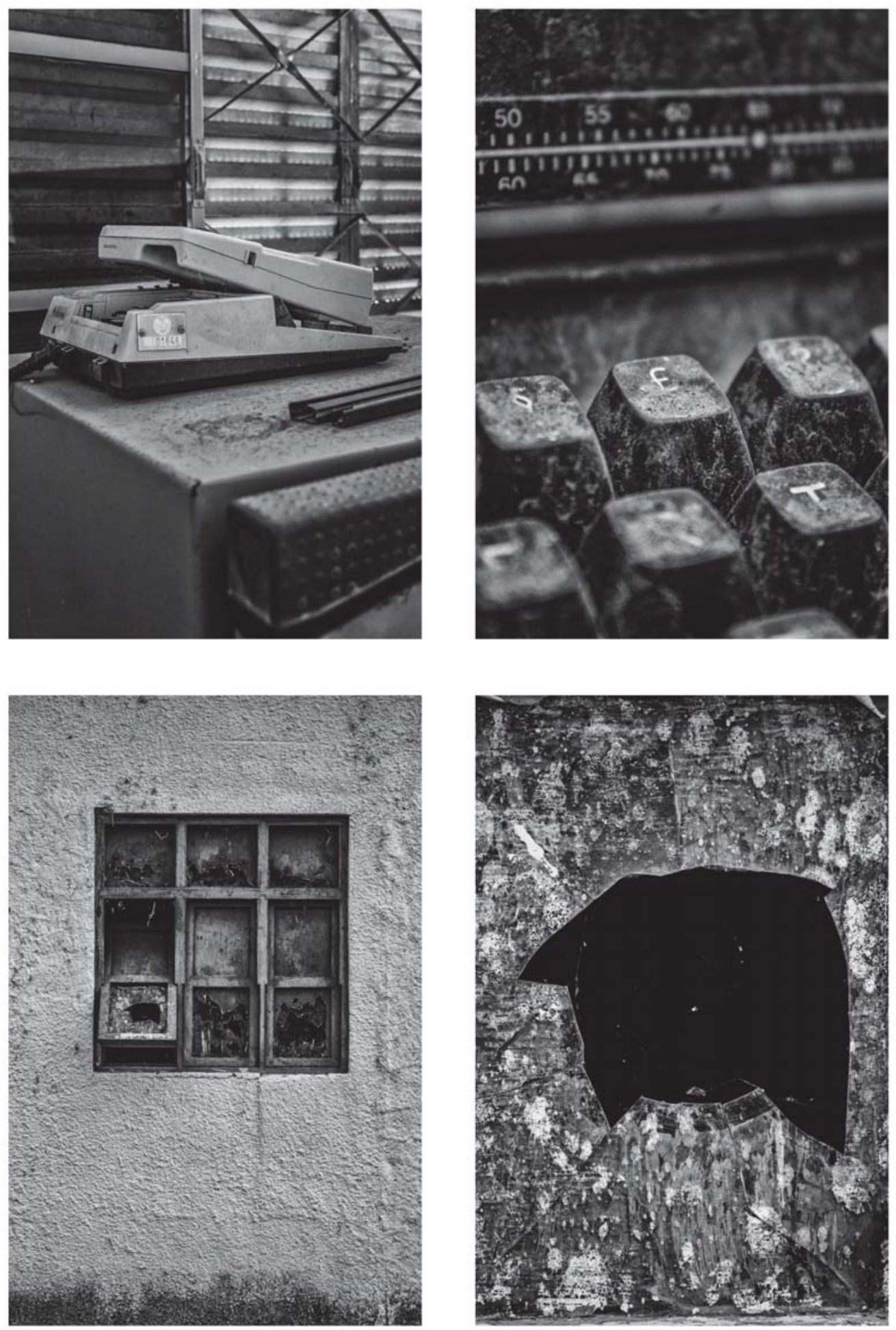

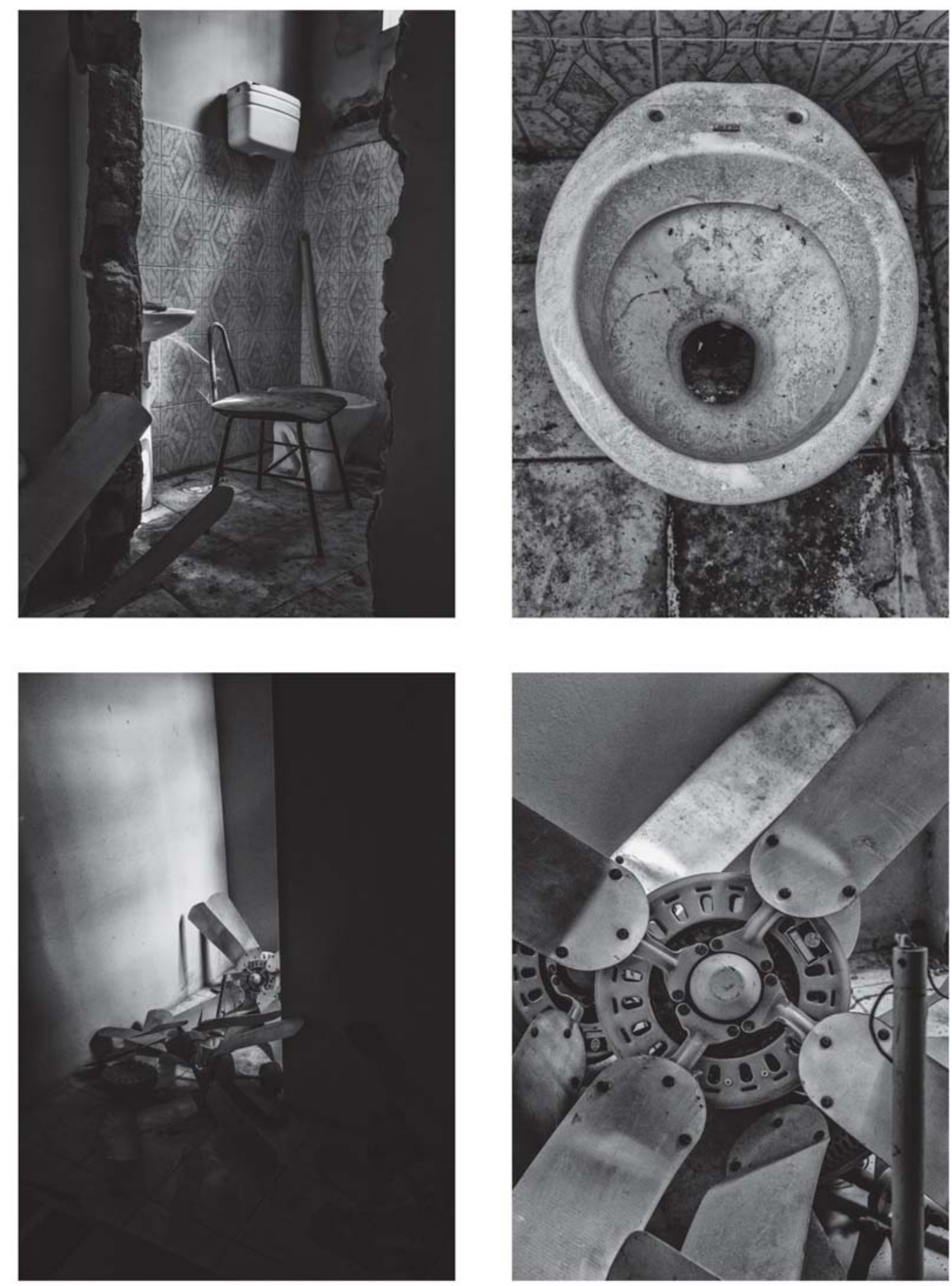

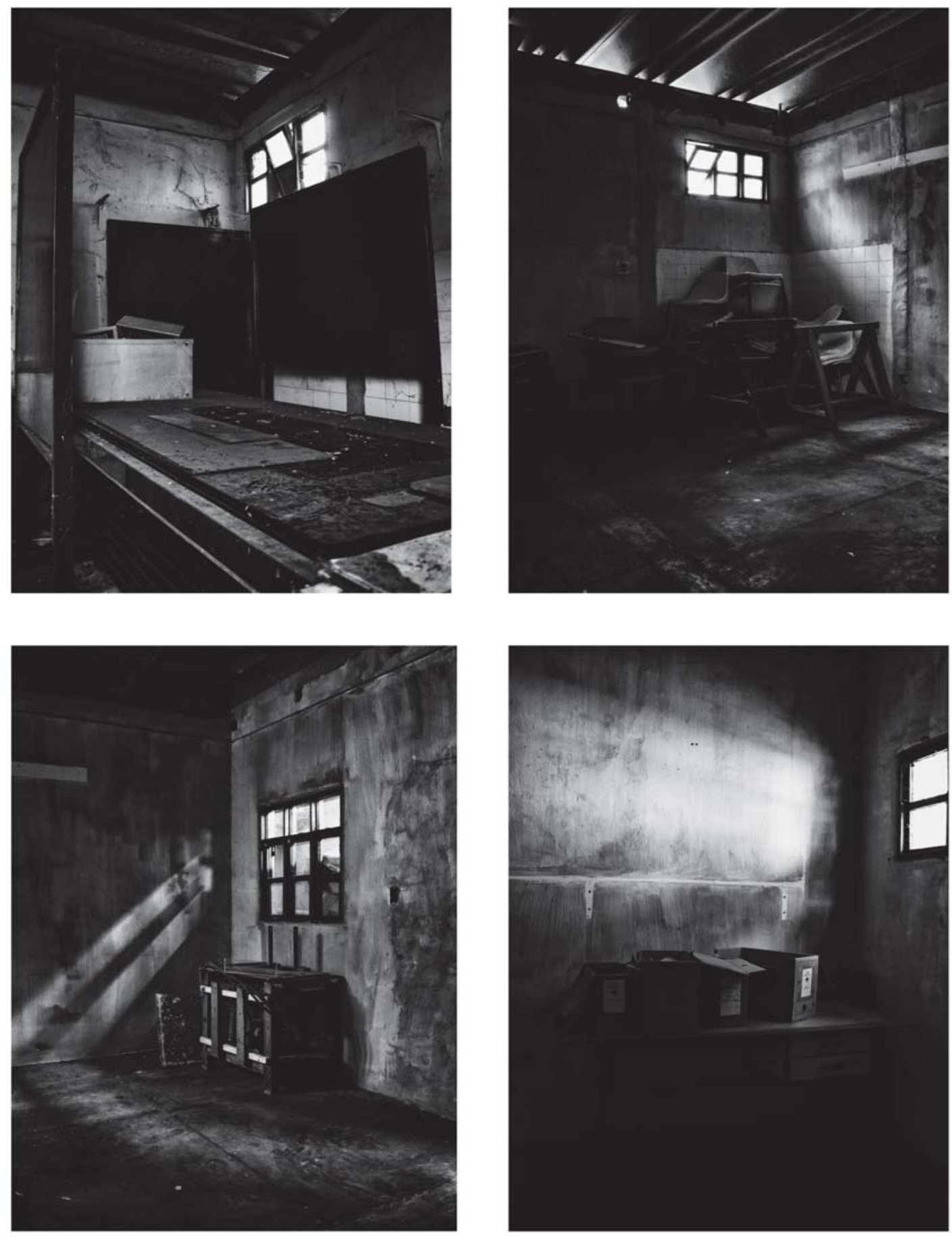


\section{REFERÊNCIAS}

ACHUTTI, Luiz Eduardo Robinson. Fotoetnografia: um estudo de antropologia visual sobre cotidiano, lixo e trabalho. Porto Alegre: Editora da UFRGS: Tomo Editorial, 1997.

ACHUTTI, Luiz Eduardo Robinson. Fotoetnografia da Biblioteca Jardim. Porto Alegre: Editora da UFRGS: Tomo Editorial, 2004

BUCHLI, Victor; LUCAS, Gavin. The Absent Present: Archaeologies of the Contemporary Past. In: BUCHLI, V.; LUCAS, G. (eds.). Archaeologies of the Contemporary Past. Londres: Routledge, p. 03-17, 2001.

DARLING, Anne. Storytelling with photographs: How to create a photo essay. Disponível em: https://photoart.zone/wp-content/uploads/2017/05/Storytellingwith-Photographs-How-to-Createa-Photo-Essay-Anne-Darling-1.pdf. Acessado em 17 de novembro de 2018.

FIUZA, Beatriz Cunha; PARENTE, Cristiana. O conceito de ensaio fotográfico. Londrina: Discursos Fotográficos, v.4, n.4, p. 161-176, 2008.

GONZÁLEZ-RUIBAL, Alfredo. Archaeology of the Contemporary Past. In: SMITH, C. (ed.). Encyclopedia of Global Archaeology. Nova Iorque: Springer, p. 1683-1694, 2014.

PÉTURSDÓTTIR, Póra; OLSEN, Bjønar. Imaging Modern Decay: The Aesthetics of Ruin Photography. Journal of Contemporary Archaeology, v.1, n. 1, p. 07-56, 2014.

SHANKS, Michael. Photography and Archaeology. In: MOLYNEAUX, B. L. The Cultural Life of Images: Visual Representation in Archaeology. Londres: Routledge, p. 73$107,1997$.

SHANKS, Michael. Introduction. In: SHANKS, Michael. The Archaeological Imagination. $1^{\mathrm{a}}$ ed. Londres: Routledge, 2012a. SHANKS, Michael. The Materiality of the Invisible: An Exibition. S.1.: s.n., 2012b. 